\title{
Article
}

\section{Evaluative Mediation (Part II), Deployment}

\author{
How to Deploy Evaluative Mediation?
}

\author{
Martin Brink*
}

\section{Introduction}

The previous issue of $\mathrm{CM}^{1}$ explored whether or not evaluative mediation is to be considered as a working method in itself, or merely the rendering of an opinion on what might be the outcome of adjudication or what according to the perception of the mediator, could be a reasonable outcome of the mediation itself. It concluded that, in the case of mediation, there is a flowing dynamic whereby the merging of one approach into another is not always clearly marked and that a working method ought not to become a straightjacket. Many actions and interventions by mediators, which have been described as evaluative - such as pressing the parties to accept a certain solution - are either directive or are an impingement on party autonomy (pressing), but do not necessarily constitute evaluation or an evaluative working method. A mediator can, in many shapes and forms, let his or her own preference or opinion be known, but that will constitute evaluation and it is not indicative of an entire working method. I consider evaluation, however packaged, to be the rendering of an opinion on what might be the outcome of adjudication or what, according to the perception of the mediator, could be a reasonable outcome of the mediation; this does not mean that it is a working method. Still, there are plenty of questions of interest remaining, for example, how to deploy evaluation and, even if it were to be considered as a

Martin Brink PhD is Editor in Chief of this Journal, mediator and arbitrator at Utrecht and The Hague, The Netherlands.

CMJ 2020/No. 1, pp. 12-20. working method, what are the do's and don'ts to watch out for.

Evaluation ought not to be an impingement upon party autonomy or be a breach of the ethical standards applicable to mediators. Any sort of adjudication, on the part of someone who agreed to act as mediator, should only happen when the parties have agreed to the evaluation. The expression of an opinion, or a judgement, on the part of a mediator - even when there is no commitment of the parties to accept it - may have a serious impact on the dynamics and on the result of a mediation. It behoves the mediator, before issuing an opinion or judgement, to have agreed with the parties on the question of switching roles. What matters, in any event, is that there will have been prior informed consent given by the parties. This means that, preferably, the various options, and the consequences of those options, will have been explained to them before they are asked either to consent to a certain approach, or not to consent..$^{2}$ In the absence of a clear understanding with the parties to agree to evaluation or adjudication, a mediator, in principle, ought to abstain from expressing an opinion or judgement. By expressing an opinion or judgement, a mediator, most likely, risks compromising his or her own position, more than that of the parties. Even aside from a possible breach of applicable ethical codes, the mediator, in such a case, runs the risk of losing the trust of the party at the least positive end of the relevant opinion or evaluation. This may, in particular, occur in the absence of an explicit request made by both parties to hear what the mediator thinks of the case. Should the parties jointly request a (non-binding) evaluation, there would not tors and Informed Consent: Warning the Unwary. Ohio State Journal on Dispute Resolution, 21(1), 45. 
seem to be any objection to the mediator letting the parties know how he or she views the case, notwithstanding the serious aforementioned risk of possibly forfeiting the trust of one, or even both, of the parties. ${ }^{3}$ There is no harm, I believe, in a mediator making recommendations, as long as these recommendations do not come in the form of a prescription, an opinion or a judgement. Very often, parties benefit from recommendations, in the form of a creative way of rethinking a solution, particularly - as I like to call it - in the form of sending up a balloon, which the parties can either grab and hold onto, or they can decide instead to put a pin in it.

\subsection{Self-Determination Remains the Key}

In this Part II of the contribution to CMJ, the question will be discussed how, in practice in mediation, the art of evaluation may be deployed. This will be done by consulting doctrine and deriving therefrom the most relevant points of attention in the event that a mediator was to consider crossing the line between facilitation and evaluation. In any event, there clearly is a solid relationship between subject matter expertise - of whatever kind - and evaluation. Without possessing subject matter expertise, a mediator ought, at all times, to refrain from giving an evaluation of material aspects of a case. Evaluation in mediation is often associated with subject matter expertise in the legal field:

What is evaluation? It is a process in which a neutral expresses an opinion as to the likely outcome or value of a legal claim or defense were it to be adjudicated. ${ }^{4}$

Nevertheless, now that 'evaluation' means to systematically determine a subject's merit, worth or significance, it need not be limited to legal appreciation.

\section{Hybrids of Evaluation}

A distinction is to be made between evaluation and what has been called a mediator's proposal. In Part I of this series, it was pointed out that the notion of a 'mediator's proposal' - whatever that may mean exactly - is not a synonym for evaluative mediation. The general perception is that a mediator's proposal is:

a settlement proposal that the mediator makes to all parties, and each party is requested to accept or reject it, on the exact terms proposed, in a confidential communication to the mediator. It calls for either an unconditional 'yes' or 'no' response, without modifi-

3 In certain jurisdictions the mediator expressing a legal opinion - depending on his or her qualifications - needs to be careful not to become engaged in the unauthorised practising of the law. This may particularly apply when one or both parties in a mediation are without legal representation.

4 Golann D. \& Aaron M.C. (2010). Evaluation in Mediations in AAA Handbook on Mediation (2nd ed.). New York: JurisNet, p. 328. cation, and the mediator is not permitted to disclose the responses that he or she receives, unless both responses are 'yes.' Thus, if one party says 'yes' and the other party says 'no,' the one who said 'yes' will not be prejudiced if settlement negotiations (or subsequent mediations) or litigation occur at a later stage. ${ }^{5}$

It is certainly possible that the proposal made by the mediator reflects his or her opinion or judgement of what an equitable outcome of the mediation would entail, but it may equally be just a totally random compromise between positions in the negotiations.

One kind of mediator's proposal could be that one party might want to consider a certain outcome conditional on the other party accepting that outcome. The framing is such that there is deemed to be no offer if the other party does not declare its position first: 'if party $\mathrm{A}$ is willing to accept X, I am willing to consider X as well', rather than 'I am willing to consent to $\mathrm{X}$, if the other party will accept X'. The result of the latter phraseology is that $\mathrm{X}$ will have been given away before it becomes clear what the other party thinks or what they will most likely do. Whereas, in the former formulation, nothing is lost if the other party is not willing to first accept X. If this formula is recommended to both parties at the same time, neither of them will risk giving away $\mathrm{X}$, if the counterparty is not willing to accept X.

$\mathrm{X}$ might be something that the mediator can suggest, having heard both parties, yet without expressing an opinion as to the reasonability or fairness of X. A word of warning is that a suggestion, as considered earlier, should never be made before there is a reasonable estimation of the zone of potential agreement. I have fallen into the trap of suggesting something to the parties at too early a stage, although in an abstract and non-committal manner, only to find out that the amount suggested was way off the mark when it came to meeting the expectations of one of the parties, in nominal terms. Another hybrid form of evaluation is Early Neutral Evaluation, an open-ended procedure involving evaluation by a neutral, whereby the parties may choose how (or how not) to make use of the opinion or judgement of the neutral evaluator. ${ }^{6}$ Where the parties opt for Early Neutral Evaluation, they agree to follow a process vis-à-vis a third party, without the authority to decide on the outcome of the dispute (the evaluator), who nevertheless, at a given point, may render an opinion or judgement. An opinion or judgement will be made known only at the request of the parties, and not before the parties will have pleaded their case, as might be done, were it to be litigation in court. The intention is to act out a form of moot litigation by the parties in order to test the strength of their arguments and to come to the core of the issues at hand, with the help of the evaluator. The evaluator will be someone with subject matter expertise

Hochman S.A. (2012). A Mediator's Proposal - Whether, When and How It Should Be Used. Retrieved from www.mediate.com/articles/HochmanS1. cfm (consulted on 4 April 2021).

6 Elaborately explained in Brazil W.D. (2012). Early Neutral Evaluation. Chicago: American Bar Association. 
in the field of the dispute in question, rather than with mediation skills. The process is confidential, form free and participation is based on prior consent. The exchange of documentation and arguments takes place in an informal manner. After having heard the arguments and studied the briefs and other documentation, the evaluator will form an opinion and put it in writing, in a sealed envelope. The parties are then given a choice to either discover the contents of the envelope - at their discretion, being either binding or non-binding - or to opt for mediation or to still decide to proceed to litigation. If the choice is made to accept the opinion as outlined in the sealed envelope, this will end the process. The idea is that the parties will be able to come to an informed decision about continuation or termination of their dispute, after having delivered and received all arguments, for and against, and having obtained the opinion of a knowledgeable third party. It is, as already said, up to the parties to choose whether or not to learn the opinion of the evaluator and whether or not to consider this opinion as binding. Early Neutral Evaluation sits somewhere between evaluation and a mediator's proposal.

An important feature of evaluation in mediation, apart from Early Neutral Evaluation and a mediator's propos$\mathrm{al}$, is that, preferably, it will be the ultimum remedium. Only at the very end, when there is nothing more to be gained, when nothing further is ventured and when all will otherwise be lost because an agreement between the parties will almost certainly not happen, the mediator may then consider on impinging upon the parties' autonomy. Nevertheless - although not all mediators abide by this rule - and solely as a matter of principle a mediator ought not to cross the line of party autonomy without express consent and, quite likely, without adopting an agreed change of role. Otherwise, one of the core values of mediation - that is, self-determination may be lost from sight. The truth is that, sometimes, parties benefit from the clarity rendered by learning the view of a mediator who is also an expert in the relevant field, but there remains a thin line between helping the parties to move towards a solution and impinging on party autonomy. It also makes a difference whether evaluation in mediation is invited or uninvited.

\section{The Mediator's Role}

Everyone has an opinion, so too does a mediator. One cannot not have an opinion. A mediator is not 'a potted plant'. ${ }^{7}$ I believe a mediator is entitled to have an opinion and also to express an opinion, on condition that the moment, the tone of voice and the manner of expressing an opinion is chosen with care and being mindful, in full consciousness, of the risks involved. Once these factors

7 Ralston R.H. (1994). Effective Advocacy and Mediation in ADR for the Defense: Alternative Dispute Resolution (p. H-1, H-3). Chicago: Defense Research Institute, Inc. are taken fully into consideration, a mediator would be well advised not to be too easily enticed into expressing an opinion. ${ }^{8}$ A mediator is not a judge, an arbitrator or a neutral evaluator. In the event that the opinion or judgement of the mediator is deemed to be interpreted as an expression of who, or what, is right or wrong, the mediator ought, in preference, to first discuss the possible impending change of role with the parties. This change of role should be clearly marked as an event in time and should not be casually slipped into or should not go unnoticed by the parties. The mediator must ascertain beforehand that the parties are desirous to learn his or her opinion or judgement, in full awareness that a confirmative response by the parties, as a rule, clearly marks the end of the role of mediator. Clarity will also have to be brought to bear, and carefully assessed, as to whether or not the parties want to accept the opinion or judgement as being binding. After having expressed an opinion or judgement, the mediator can no longer be considered as being neutral.

An estimation of the outcome of litigation or arbitration may be done in various ways, for example, by saying that a court will probably not endorse a certain standpoint or by wondering aloud whether a court might indeed concur with a particular standpoint. These are two completely different interventions. One is the expression of an opinion about a standpoint of a party; the other represents not much more than the expression of the mediator's own doubt. Both interventions may be considered as evaluative, although only one is the expression of a judgement, while the other may, or may not, be depending on the audience. The expression of the mediator's own doubt in a caucus carries a different weight, as opposed to expressing his or her doubt about the standpoint of one of the parties in plenum.

These examples make it clear that hard and fast rules, as to what and when an intervention forms an impingement on the autonomy of the parties, are not so readily available. Yet, the norm (as a core value) remains that it is not intended that the mediator will defer from a neutral position or will no longer respect the autonomy of the parties. The other norm, in my view, is the intention of the parties and whether the mediator will be able to retain their trust. The key elements of autonomy of the parties, the right to self-determination - also referred to as 'democratic participation' or 'democratic decision-making" - and maintaining the trust of the parties in the mediator, provide the cornerstone for fostering respect for the profession of mediation.

Evaluation is a legitimate weapon in the mediator's arsenal, one that can be either effective or explosive depending on how and when it is used. ${ }^{10}$

8 Where there is mentioning of opinion this may include the rendering of a judgement, depending on the context, but then it is not necessary to keep referring to both options.

9 Van Muijden M.S. (2007). Mediation en de vaststellingsovereenkomst ('Mediation and the Settlement Agreement'), 's-Gravenhage, Sdu Uitgevers.

10 Golann D. \& Aaron M.C. (2010). Using Evaluations in Mediation in AAA Handbook on Mediation (2nd ed.). New York: JurisNet, p. 238. 
Kovach \& Love ${ }^{11}$ mention a number of activities of mediators which they consider evaluative, but acceptable, within a facilitative mediation frame:

We see the following 'evaluation' activities of a mediator as essential parts of a mediator's facilitative role: reframing components of the conversation so that the parties can hear them without reacting defensively; structuring the bargaining agenda to maximize the opportunity for successful collaboration between the parties; probing assessments and positions to ensure that a party properly understands and considers counter-assessments and positions; challenging proposals that might derail the negotiation or that seem unrealistic or suboptimal; urging parties to obtain additional resources and information; and sometimes making suggestions about possibilities for resolution in order to stimulate the parties to generate options.

Relevant points for attention are to be found in a consultation document for a policy paper published by the Board of Directors of the Association for Conflict Resolution in the United States in September 2004, under the title The Authorized Practice of Mediation. The intention was to formulate a guideline to distinguish between what was seen as correct and incorrect behaviour of a mediator. The relevant working party identified a number of actions by mediators which were deemed to be evaluative. The first three were considered improper, while the last two were considered acceptable.

1. Advise parties about their legal rights or responsibilities;

2. Apply legal precedent to the specific facts of the dispute;

3. Offer any personal or professional opinion as to how the court (judge or jury) in which the case has been filed will resolve the dispute;

4. Provide any personal or professional evaluation of the strengths and weaknesses of the case, either directly or implicitly; and

5. Recommend a specific course of action.

In any event, informed consent has to be strived for. It is clear that the border between what may, and what may not, be considered appropriate, will, to a large extent, depend on the manner in which one or more of the actions listed under 1 to 5 above will be translated and framed in communication with the parties. For example, the opinion of the mediator that one of the parties, legally, has hardly any case, can be translated into questions such as 'Did you get legal advice on this issue?' or 'Did you hear what the other side's counsel mentioned about the legal validity of your claim, in the event that the court would have to rule on this matter'? Rick $^{12}$ postulates:

11 Kovach K.K. \& Love L.P. (1998). Mapping Mediations: The Risks of Riskin's Grid. Harvard Negotiation Law Reviews, 3(71), 71-110.

12 Rick A.T. (2009). Evaluation within Mediation and the Ideal of Neutrality. American Journal of Mediation, $3,1$. implicit case evaluation by mediators is impossible to avoid.... Given that some form of evaluation will be present in every mediation, and that the boundaries of appropriate mediator conduct are far from clear, the best solution lies in modifying the context of the mediation rather than the conduct of the mediator.

Modifying the context of mediation can be done by switching roles or stipulations. It is important that parties should be able to rely on the qualifications of mediation in order to know what to expect. Neither should any other dispute resolution procedure, other than mediation, be labelled as mediation, in an effort to gain the protection of rules, statutes, or of other governing authorities pertaining to mediation. ${ }^{13}$

As already stated, a mediator cannot not have an opinion. It will not always be easy to hide this opinion completely from the parties. Mediators are ordinary people and what is important is how they handle their feelings and opinions, preferably being well grounded in deploying mediation skills. Laflin ${ }^{14}$ put into words what Rick may have intended with 'modifying the context of mediation':

If the neutral subsequently recognizes that the process has edged into, say, neutral evaluation, then ethics demands that the mediator not simply continue the process under the guise that the parties want 'evaluative' mediation. He or she should inform them that the process they initially agreed to has changed.

Also Golann and Aaron ${ }^{15}$ warn against the pitfall that the divide between facilitation and evaluation may, unintentionally, be crossed without noticing it:

Mediators may be less successful than they think at hiding their opinion about the merits. Reality testing is a spectrum in which the line between mere testing and evaluation is not always clear. For example, a phrase such as 'What are your thoughts on the causation issue?'16 is unlikely to be controversial. But such commonly-asked questions as 'Do you think there's a problem on causation?', 'What would you say in response to their argument on causation?', 'Don't you have a causation problem here?', or 'You don't think that's an issue?' are increasingly likely to be interpreted as evaluative opinions. Even if the language used by a mediator is scrupulously neutral, his or her feelings about the strength of an argument may well show unconsciously in facial expressions and body language.

13 Also Standard VI A under 6 of the Model Standards of Conduct for Mediators as established by the American Arbitration Association, the American Bar Association and the Association for Conflict Resolution in September 2005

14 Laflin M.A. (2002). Preserving the Integrity of Mediation through the Adoption of Ethical Rules for Lawyers-Mediators. Notre Dame Journal of Law, Ethics and Public Policy, 14, 479.

15 Golann D. \& Aaron M.C. (2010). Using Evaluations in Mediation in AAA Handbook on Mediation (2nd ed.). New York: JurisNet, p. 238.

16 Causation issue is about the relationship between the cause of an event and damages resulting therefrom. 
Golann and Aaron believe it is realistic to accept that evaluation my occur during a mediation. Rather than contradicting this or denying it, one might reflect beforehand on how to deal with it, just in case the moment occurs or can hardly be avoided. It is advisable for a mediator to always be mindful of the words chosen when formulating a question or an observation. Because mediation is based on the principle that the parties themselves come up with a solution, evaluation should be the last resort. Preferably, evaluation is only used upon the expressive request of all parties involved, or as an absolute last resort, sometimes referred to as 'BATL', the Best Alternative to Litigation. Once a mediation has come to this stage, there is generally only something to be gained and not much more to be lost.

A mediator can, in the first instance, consider not rendering an evaluation by himself or herself, but, instead may propose to engage a third party to do so, that is, someone who is not a participant in the mediation. The advantage of this approach is that the mediator can remain neutral and also that an expert can be consulted with, perhaps, even more (in depth) subject matter expertise than the mediator. An outside expert can be selected who possesses specific knowledge of the issues at stake, but not necessarily having mediation skills. This will enable the mediator to stay focused on the process of facilitating the communication between the parties. The downside of this option is that it will involve extra costs and probably loss of time. On the other hand, some delay in the process required for consulting a third party may occasionally offer a cooling off opportunity for the parties, after their initial meetings, thus bringing the possibility of allowing their awareness to grow on the fact that reaching a solution is preferable to continuation of the impasse. At the same time, however, it may also lead to a falling back on initial positions and a hardening thereof. Each of the parties will seek to influence the expert to be consulted and endeavour to win him or her over to their own viewpoint.

It may also transpire that the parties may not want to lose time and might ask the mediator to express an opinion or judgement. Another reason to ask the mediator could be that the parties cannot agree on which expert to consult. In such a case, the mediator might still try to remain impartial by suggesting that an expert will be recommended or appointed by a professional organisation of experts, or by a court. If that does not work, as a last resort, the mediator can also ask to be allowed to appoint an expert. On the basis that, whatever the expert decides, the outcome will most likely be associated by the party at the receiving end of the least favourable options with the influence of the mediator.

\section{Evaluation}

Should a mediator consent to express an opinion, or render an evaluation as to what the strong and weak points of a case are, preferably that opinion or judge-

ment will not be the expression of the mediator's own judgment, but it will, instead, be based on a norm according to general or specific doctrine or caselaw. In the event that the mediation fails, and the issue in dispute is brought before a judge or arbitrator, what the mediator thought of the issue will not be relevant. What is relevant is what a third party, judge, arbitrator or expert would find. Should it come to that, to predict even remotely accurately what a court, arbitrator or expert would say, in the end, is virtually impossible. So, the more information, doctrine, caselaw and other best practice can be invoked on which to base an evaluation, the better. Parties are not well served by subjective opinions of an individual mediator. Aside from the limitation of statutes, or in other very limited situations (e.g. legal standing) it is, as said, not really possible to predict the outcome of litigation. Lawyers, not mediators, are trained to interpret facts and to translate these into legally relevant parameters, as the basis for an evaluation of the possible outcome of litigation. Even lawyers are as often wrong as they are right, if not more often wrong. In the event that litigation continues until a verdict is reached, invariably one attorney wins and another loses, so one might say that at least one of the two attorneys involved did not accurately assess the strengths of the case. From my own experience as a substitute magistrate in a Court of Appeals, I know that the ultimate outcome of a case is often the result of considerable deliberation, which may equally have resulted in another outcome. The lesson here is that predicting the outcome of litigation is very difficult, if not impossible. A judge, in addition to legal training, does not necessarily possess subject matter expertise in the field of the conflict in question, so the outcome of a case need not be in line with what an expert in the field might have found either. Also, one has to bear in mind that 'there is no single legal answer to multiple truths'.

A distinction can be made as to the nature of the recommendation or the evaluation which may be deployed. Golann and Aron ${ }^{17}$ distinguish between a standpoint or recommendation about the material content of an issue which they call merits recommendation and a standpoint or recommendation about the reasonableness of a solution, which they call settlement recommendation. They see it as unethical to use the weight of the legal strengths and weaknesses of a case (merits recommendation) as a basis for recommending what would be reasonable (settlement recommendation). It must be clear what kind of evaluation is performed.

When a mediator considers an evaluation, the following suggestions made by Golann and Aaron ${ }^{18}$ - to which I have added some of my own - may offer guidance to navigate carefully:

- Try as much as possible to limit the object of the evaluation, limit the issues. It is not always neces18 
sary to involve the entire complex of issues which is keeping the parties apart.

- Try to select one or more issues about which the parties seem to be able to reach an agreement - if only for discussion purposes - and base an evaluation on those issues, piggyback whenever possible.

- Ask whether evaluation might help. It may serve the parties, or one of them, to justify a certain outcome, for example vis-à-vis superiors or others. Think about who needs to be influenced. Subject matter expertise on the part of the mediator may weigh in even more in this respect than otherwise. The authority of the mediator, as an expert in his or her field, can contribute to the degree of acceptance of the outcome of the evaluation.

- Consider and discuss how an evaluation is to be organised, make choices for an effective format. This relates to procedural issues. Which information will be shared and to what extent? Will the parties be given the opportunity to plead their case, have their day in court? Will the evaluation take place in caucus or in the presence of all parties? Golann \& Aaron prefer not to allow a kind of semi-litigation and have a preference for evaluation in caucus. Their belief is that evaluation is intended as a reality check and the caucus will allow more room to formulate the various arguments in such a manner that these can be heard and comprehended by the party concerned.

- It is important to avoid the impression by either party that different evaluations are taking place in different rooms. It has been suggested to avoid that impression by writing down the bullet points of the evaluation on a flip-chart and to use the same flipchart in both rooms, as a road map for an explanation.

- Much is to be said - if circumstances will allow - to work on the basis of understanding based mediation. ${ }^{19}$ This means - certainly when parties are assisted by attorneys - to request the parties and their attorneys to explain their point of view to each other in a plenary session and to listen to one another. This will make both parties hear an alternative view to their own. Their own attorney will have highlighted most, if not all, of the arguments in favour of their case, but the explanation of the other party's attorney may make it clear that there are more ways than one to look at the issue. This will sometimes be more illuminating than evaluation. The presence of a mediator will make certain that the parties will listen without interruption and will hopefully create an atmosphere that allows parties to ask verification questions and to clear up mutual misunderstandings.

- It is important to pay attention to the tone of voice, the manner of expression, the culture of the parties and to what they have in common, so be mindful of

19 Friedmann G. \& Himmelstein J. (2008). Challenging Conflict, Mediation through Understanding. Chicago: ABA Publishing, pp. xxxv-xxxvi. language, culture and communality of the parties. If one wants the parties to hear and understand each other, it is 'the tone that makes the music'. Subject matter expertise may contribute to communicating with the parties in their own language, and perhaps even in their own jargon, and may even help to connect to what they have in common.

- Humour, used with care, and at the right moment, ${ }^{20}$ as well as one-liners applicable to a situation, may sometimes offer an opportunity to express an opinion or a sentiment. ${ }^{21}$

- Being empathetic will help. To recognise and acknowledge concerns on the part of a party who is being confronted with the fact that a certain viewpoint will be difficult to uphold may contribute to the extent that the message can indeed be received. An interesting example of empathy is something I once heard from a mediator who did personal injury cases. He identified 'a period of mourning', also in case of loss of an argument. When someone loses someone or something close to one's heart, a partner, a child or a limb, it takes a period of mourning to come to terms with that loss. Sometimes, one never gets over a loss. Letting go of an argument that has been held on to for a long time, may also take a while. It is important that the person involved recognises the fact that saying goodbye to a sincerely felt belief or point of view may be quite difficult.

- Much can be gained by having parties appreciate the different paradigms in a conflict, so it may be advisable to emphasise differences in perspective. It is not always easy for parties to accept that the same complex facts or circumstances can be viewed from a different angle by someone else. The explanation, quoting M. Gandhi - that where two parties in a conflict are sincere, they are both right - often proves useful. A less light-hearted example is that of a peace negotiator in a war zone who is negotiating with the murderer of his or her people. The same, however, also applies to the person at the other end of the table. A very helpful image to present to parties is the picture of two people standing opposite each other and, on the floor between them, lies a figure, which one insists is a six while the other maintains that it is a nine. When using this image, I generally add that it does not make any difference whether the issue concerns a figure on the floor or whether it concerns their dispute, however voluminous the file is.

- It may be of help to explain to the parties that one cannot agree with what someone says, but that this needs to be distinguished from who he or she is. In many cases, representatives of parties, or the parties themselves in a dispute, act in the role of trying

Cruthirds K.W. (2010). The Impact of Humor on Mediation in AAA Hand book on Mediation (2nd ed.). New York: JurisNet, p. 267.

21 MacPherson R. (2010). Forty Lines Mediators Can Hang Clothes On: No Really! in AAA Handbook on Mediation (2nd ed.). New York: JurisNet, p. 451 . 
to serve their family, company or an interest that is important to them or to others. They may be seen as only messengers, in this respect, and do not deserve to be judged harshly as persons, even if they are in total disagreement with all of the arguments.

- The more the mediator can distance him or herself from the evaluative opinion or judgement, the better. The possibility to engage a third party with specialised subject matter expertise has already been mentioned, as well as the option to select such an expert oneself.

- It may be helpful to try to make an evaluation more objective by engaging a technique known as decision analysis, ${ }^{22}$ economic analysis ${ }^{23}$ or risk analysis. ${ }^{24}$ This can be done by using software,$^{25}$ which offers decision trees, ${ }^{26}$ which allow the parties to compare possible scenarios on the basis of their own estimations and evaluations. The idea is to complete a decision tree, which will render an analysis of all options, by constantly asking 'what if' and expressing the replies in a chance percentage. As Slavitt ${ }^{27}$ observes:

- Risk analysis is not a panacea for settlement of disputes. Fundamental differences of opinion about possible outcome or the likely range of damage could still preclude settlement. On the other hand, there will be situations when risk analysis will promote settlement and help the parties with each other or with the mediator.

The use of software such as this allows the mediator to remain at a distance from the hopefully growing awareness of downward risks by the parties as a result of completing a risk analysis themselves. I will, later in this article, refer to what I have dubbed the Brink-Bar which is an instrument that may also stimulate the parties to question themselves, more in depth, as regards the relativity of their case.

- As explained earlier, it is important to ensure that there is, or will be, subject matter expertise accessible to the parties. If the mediator does not possess (sufficient) subject matter expertise, this ought to be sourced from elsewhere. It is possible for a mediator to seek advice. With confidentiality in mind, this will require the parties' consent. If costs are involved, they will have to approve this expenditure beforehand.

- Particularly in cases where there are no lawyers, or other expert counsel present at a mediation, the parties should only be asked to agree to a settle-

Aaron M.C. (1995). The Value of Decision Analysis in Mediation Practice. Negotiation Journal, 11(2), 123-133.

23 Philbin Jr. D.R. (2010). The Value of Economic Analysis in Preparing for Mediation in AAA Handbook on Mediation (2nd ed.). New York: JurisNet, p. 207.

24 McGuire J.E. (2010). Practical Tips for Using Risk Analysis in Mediation in AAA Handbook on Mediation (2nd ed.). New York: JurisNet, p. 343.

25 E.g. TreeAge or SmartDraw.

26 Korobkin R. (2002). Hesperian Decision Tree Prelitigation in Negotiation, Theory and Strategy. New York: Wolters Kluwer Aspen Publishers, p. 55.

27 Slavitt E. (2010). Using Risk Analysis as a Mediation Tool in Mediation in AAA Handbook on Mediation (2nd ed.). New York: JurisNet, p. 417. ment on the basis of an evaluation, after having obtained a second opinion.

\section{In Corporate Mediation}

There are multiple investigations ${ }^{28}$ indicating that, in corporate mediation, parties do not intend so much to reinvent themselves but are seeking to find pragmatic solutions. One method of exploring such solutions that are closely related to evaluation is to carry out a SWOT analysis $^{29}$ as a way to help design and ask questions. ${ }^{30}$ This is not the same as evaluation, in the sense of predicting the outcome of litigation.

Mediating commercial cases combats overconfidence because it typically encompasses frank and mutual analysis of alternatives to agreeing consensually. Comparing what emerges as the best terms available during mediating with these alternatives is a core component of commercial dispute mediation. Effective mediators promote the development of greater information regarding mediation alternatives by discussing, usually in caucuses, strengths, weaknesses, gaps, inconsistencies, and vulnerabilities concerning specific dimensions of anticipated mediation goals.

Because commercial dispute resolution usually occurs in the shadow of adjudicatory alternatives, much of this conversation concerns specific information regarding case analyses and outcome forecasts. Typically occurring after disputants have presented their views, concerns, and opinions fully, these conversations often begin with discussions of analytic strengths and bases of favorable predictions. Listening carefully, mediators can convert this information into questions to ask counterparts regarding potential vulnerabilities and weaknesses in their legal positions and outcome forecasts.

Mediators then tactfully phrase and respectfully ask these questions. Responding to these inquiries permits counterparts to learn and assess these contrasting perspectives. Using questions rather than statements allows commercial clients to hear pros and cons of adjudicatory analyses and predictions discussed in non-adversarial information-oriented manner rather than persuasion-focused, settings. These discussions often help clients understand why and how they need to adjust their views of adjudicatory outcomes in order to form more realistic expectations of settlement possibilities and proposals.

An instrument which has served me well as a mediator to help parties evaluate their position themselves, and

28 Vide a.o. Global Data Trends and Regional Differences, Report IMIGlobal Pound Conferences. Retrieved from https://imimediation.org/research/ gpc/series-data-and-reports/ (consulted on 20 October 2021) and the report of the ZAM/ACB Questionnaire, published 17 December 2018 on opportunities and difficulties in corporate mediation.

29 Strengths, Weaknesses, Opportunities and Threats.

30 Peters D. (2010). It Takes Two to Tango, and to Mediate: Legal Cultural and Other Factors Influencing United States and Latin American Lawyers' Resistance to Mediating Commercial Disputes. Richmond Journal of Global Law and Business, 9(4), 381-429. 
to choose a pragmatic solution, is to draw a bar on a flipchart, dividing it into four sections. ${ }^{31}$ In these sections, from left to right, the following words are written: IDEAL - DEAL - BATNA - WATNA. This drawing may help to explain to parties that an ideal world does not exist. The narrative to explain this drawing reads as follows: It is a wonderful sunny day and one sits in a lounge chair in one's garden, where the birds sing and, on the side table, is one's favourite drink. Thinking about the dispute at hand, one can dream up an ideal solution, with optimal outcome. At the other end of town, where the sun also shines and the birds also sing, the other party also sits in a lounge chair with a favourite drink on a side table, while also coming up with an ideal solution with optimal outcome (section IDEAL). One problem is that these two ideal solutions are not the same. Then comes Monday, it is raining and one has to go back to the office and one knows from experience that if one wants to get a deal with the other, one has to compromise and make concessions (section DEAL). If one does not succeed in reaching an agreement, the question needs to be answered as to what the price will be of not compromising and missing out on a DEAL. What is the cost of failing to reach an agreement and what is the best alternative to a negotiated agreement (section BATNA). The answer to that question may have to be compared to the situation whereby the relationship deteriorates further into a stage where it becomes lose-lose and it no longer matters what the outcome will be, as long as the other party does not come out as the victor; this is the worst scenario to a negotiated agreement (section WATNA). The parties are asked to consider carefully all four situations featured in the bar and to think through the consequences of each of the situations materialising.

As a result of the tension in a mediation process, and the distraction that the presence and influence of the other party will bring, either party can easily lose sight of its own interests and priorities. This bar may help to bring the focus of a party back to what matters most to it and regain strength in order to arrive at a decision based on priorities. The bar can be used not only in caucus but also in a plenary session, so the parties can go over all four situations jointly. Attention needs to be paid to timing when one wants to use the bar. Its use is most effective at a later stage in a mediation process, after the parties have first had the opportunity to share all that they wanted to bring forward and perhaps, at this stage, they may even be going around in circles. Presenting the bar is helpful to give a new impulse when an impasse has been reached and also as possible homework for parties at the end of a session.

31 See Reijerkerk L., Hora Adema L. \& De Waart J. (2018). Brink bar in Models for Mediation, Survey and Visuals. The Hague: Eleven International Publishers, Model 43, p. 114.

\section{Conclusion}

The discourse about what does, and what does not, constitute (good) evaluative mediation practise will, no doubt, also continue into the future. I believe evaluative mediation is not as clearly distinct from, or even directly contrary to, good mediation practice, as conceptualised in the most commonly known mediation styles. ${ }^{32}$

Components of all kinds of mediation approaches may play a role in every mediation. The attempts to define and describe mediation practice in great detail stems from a wish to regulate mediation and make it susceptible to monitoring, allowing the disciplining of mediators and offering clarity as to what mediation entails for (potential) users of mediation. My mantra is that respecting the core values of mediation provides a onesize-fits-all frame for mediation, both in terms of regulation, sanctioning malpractice and offering clarity to (potential) users of mediation. A legal recognition and inclusion in ethical codes of the core values can result in a mediator, who does not respect these core values, being considered to be in breach of the service agreement, which will be the basis of the relationship between the parties and the mediator.

The core values concerned are voluntariness of frontend and back-end participation consent ${ }^{33}$ (and the freedom to end the mediation, at will, at any time), impartiality of the mediator, confidentiality and (respecting) party autonomy. These values also clearly set forth the nature of behavioural markers in sufficient detail for measurement on a performance-based competency test. Demanding respect for the core values offers safeguards against abuse and malpractice. Irrespective of what definition of mediation one wants to adhere to, or what type of interventions one wants to deploy as a mediator, the core values ought to be the universal common denominator of what mediation ought to entail. Given due observation of core values, it is liberating for all. There will, inevitably, be multiple views and feelings as to what a right approach to, or in, mediation comprises. The power that mediation is presently manifesting in today's polarised world, it owes to its flexible, form-free nature. This ought to allow a pluralistic approach. In order to gain the trust of the parties, a mediator would be well advised to start with a facilitative approach and to make it a joint decision of all involved in the mediation as to how to proceed, based on the wishes and needs of the parties, and with their informed consent, or clear acceptance, of what comes next.

It is my conviction that, given the variety of conceptualisations of mediation that populate the field, a single performance-based competency test ${ }^{34}$ is an impossible objective and a pluralistic approach will serve the public best, as long as it observes the backbone of the universal perception of mediation in the form of respecting core

32 Facilitative and transformative mediation.

33 In a number of countries, voluntariness and confidentiality no longer apply in full.

34 Other than grounded on the core values. 
values. This explains why evaluation can be part of a mediation process, with the express consent of the parties. I conclude by referring again to the quote mentioned in Part I of this article by Moberly: ${ }^{35}$

We say that the parties are entitled to self-determination. If the parties want evaluation, and believe it helps resolve their dispute, the principle of self-determination calls for allowing evaluation, not prohibiting it.

Hopefully, this Part II of the evaluation of evaluative mediation, or rather evaluation in mediation, contributes to an insight in the ways in which evaluation may be deployed in mediation. Evaluation is to be used in a manner that respects the self-determination of the parties and in order to help them to find a solution to their problem. 